\title{
Levodopa and executive performance in Parkinson's disease: A randomized study
}

\author{
BERTA PASCUAL-SEDANO, ${ }^{1} \mathrm{JAIME} \mathrm{KULISEVSKY,},{ }^{1}$ MANEL BARBANOJ,${ }^{2}$ \\ CARMEN GARCÍA-SÁNCHEZ, ${ }^{3}$ ANTONIA CAMPOLONGO,${ }^{1}$ ALEXANDRE GIRONELL, ${ }^{1}$ \\ JAVIER PAGONABARRAGA, ${ }^{1}$ AND IGNASI GICH ${ }^{4}$ \\ ${ }^{1}$ Department of Neurology (Movement Disorders Unit) and CIBERNED, Hospital de la Santa Creu i Sant Pau, \\ Autonomous University of Barcelona, Spain \\ ${ }^{2}$ Center for Drug Research and CIBERNED, Hospital de la Santa Creu i Sant Pau, Autonomous University of Barcelona, Spain \\ ${ }^{3}$ Department of Neurology (Neuropsychology Section) and CIBERNED, Hospital de la Santa Creu i Sant Pau, \\ Autonomous University of Barcelona, Spain \\ ${ }^{4}$ Department of Epidemiology, Hospital de la Santa Creu i Sant Pau, Autonomous University of Barcelona, Spain \\ (Received October 23, 2007; Final Revision May 17, 2008; Accepted May 18, 2008)
}

\begin{abstract}
Parkinson's disease (PD) patients may experience fluctuations in executive performance after oral levodopa (LD). Their relationship with the pharmacokinetic profile of LD and with distinct cognitive processes associated with frontal-basal ganglia circuits is not well understood. In this randomized, double-blind, crossover study we plotted acute cognitive changes in 14 PD patients challenged with faster (immediate-release, IR) versus slower (controlledrelease, CR) increases in LD plasma concentrations. We monitored motor status, LD plasma levels, and performance on four tasks of executive function (Wisconsin Card Sorting Test-WCST, Sternberg test, Stroop and Tower of Hanoi), $1 \mathrm{hr}$ before and over $+6 \mathrm{hr}$ after IR and CR-LD dose. Analysis of variance demonstrated significant but divergent changes in the Sternberg (6-digit but not 2- and 4-digit) test: improvement after CR-LD and worsening after IR-LD. Marginal improvement $(p=.085)$ was observed with CR-LD in the WCST, while no significant differences were seen for the Stroop or Tower of Hanoi tests. Executive-related performance after LD challenge may differ depending on the LD time-to-peak plasma concentration and specific task demands. A slower rise in LD levels appears to have a more favorable impact on more difficult working memory tests. These results require replication to determine their generalization. (JINS, 2008, 14, 832-841.)
\end{abstract}

Keywords: Cognition, Dopamine, Frontal lobe, Basal ganglia, Neuropsychology, Neuropsychological tests

\section{INTRODUCTION}

Parkinson disease (PD) is a neurodegenerative disorder in which the major neurochemical finding is a progressive loss of midbrain dopaminergic neurons.

Diagnostic motor symptoms such as rest tremor, bradykinesia and rigidity, appear when degeneration of the dopaminergic neurons of the posteroventral substantia nigra pars compacta reaches a critical point, creating a hypodopaminergic state in the lateral putamen (Damier et al., 1999; Jellinger, 1987; Kish et al., 1988).

Correspondence and reprint request to: Jaime Kulisevsky, Neurology Department (Movement Disorders Unit), Hospital de la Santa Creu i San Pau. Calle Sant Antoni M. Claret, 167, 08025 Barcelona, Spain. E-mail: jkulisevsky@santpau.cat
Besides motor symptoms, cognitive disturbances are also well recognized in PD and are present in most patients from the initial stages of the disease (Janvin et al., 2003; Lees \& Smith, 1983). While other cognitive domains may be impaired and eventually lead to dementia in PD, "frontal" type executive impairment predominates over the course of the disease (Emre, 2003). Impairment of attention and memory search strategies, slower visuomotor processing, reduced verbal fluency, impairment of organizational and constructional strategies on learning and copying tasks, and motor programming disturbances are characteristic (Peavy et al., 2001). Particularly affected are tasks that involve incremental, feedback-based learning of cue-outcome associations (Shohamy et al., 2006). Although other neurotransmitters may be deficient in advanced PD (Emre, 2003), these "frontal-type" deficits can be explained by the malfunction- 
ing of the fronto-striato-thalamic circuitry, without any neuropathological lesion other than dopaminergic degeneration (Kulisevsky, 2000). Dopamine loss in PD is not confined to the putamen but extends more ventrally in the striatum, as well as to the mesolimbocortical dopamine system (Damier et al., 1999; Kish et al., 1988) due to degeneration of neurons projecting from the ventral tegmental area and the medial substantia nigra pars compacta to the neocortex (Jellinger, 2001). Striatal (especially caudate) dopamine activity, particularly by means of $\mathrm{D} 2$ receptors, might be important for response inhibition and temporal organization of information (Cropley et al., 2006), whereas prefrontal cortex (PFC) dopamine transmission by means of D1 receptors seems to play a more prominent role in learning and working memory performance (Dreher et al., 2002; El-Ghundi et al., 2007; Mizoguchi et al., 2000). Thus, depending on the involvement of the striatum and PFC on the specific task demands, both nigrostriatal dopaminergic depletion and cortical dopaminergic deficiency may play a role in cognitive deficits in nondemented PD (Kulisevsky, 2000; Monchi et al., 2004).

Evidence from studies of experimentally induced dopamine deficits in nonhuman primates (Williams and Goldman-Rakic, 1995) and from PET studies in healthy subjects (Bäckman et al., 2000; Volkow et al., 1998) supports that working memory is especially vulnerable to dopamine loss. Dopamine D1 receptor stimulation in the PFC follows an "inverted-U" dose-response curve, whereby either too little or too much D1 receptor stimulation impairs working memory (Dreher et al., 2002; Goldman-Rakic et al., 2000; Vijayraghavan et al., 2007). According to this action of dopamine as a neuromodulator, many cognitive tasks can be differently influenced by dopaminergic replacement in $\mathrm{PD}$ (Cools et al., 2001, 2002; Gotham et al., 1988; Grossman et al., 2001; Kulisevsky et al., 1996; Kulisevsky, 2000; Swainson et al., 2000). Hence, a positive, neutral or negative effect is not necessarily dependent on a cognitive specificity of dopaminergic drugs and may be more dependent on the task-demands, the level of dopamine depletion, and the ability to buffer the intermittent excess of dopamine in the basal ganglia and PFC (Cools et al., 2001; Frank et al., 2004; Kulisevsky, 2000; Shohamy et al., 2006). Chronic dopamine replacement in de-novo PD patients using either dopamine agonists or the oral precursor of dopamine levodopa (LD) has been associated with a substantial and relatively long-lasting improvement in executive tasks (Kulisevsky, 2000). On the other hand, advanced PD patients challenged with an acute dose of oral LD may show either no changes, improvement, or a transient and taskspecific impairment in cognitive performance (Cools et al., 2001; Cools, 2006; Frank et al., 2004; Gotham et al., 1988; Malapani et al., 1994, 1998; Shohamy et al., 2006; Swainson et al., 2000) associated to the peak of plasma concentrations of LD (Kulisevsky et al., 1996) and manifested in clinical practice as cognitive fluctuations or periods of confusion after drug intake.

Cognitive fluctuations do not necessarily appear in PD patients exhibiting motor fluctuations (Witjas et al., 2002).
However, they might share some pathogenetic mechanisms that are more related to the short half-life of LD and its potential to induce abnormal pulse stimulation of dopamine receptors than to specific properties of the drug (Olanow et al., 2004). Cognitive fluctuations may also be related to the development of postsynaptic adaptive neurotransmitter changes (Chase and Oh, 2000; Oh et al., 2003; Westin et al., 2001), and to the increased dopaminergic turnover in dopamine synapses (de la Fuente-Fernández et al., 2001). Thus, dopamine formed from intermittent doses of LD required for motor benefit approaches a threshold beyond which further increases may interfere with the processes normally involved in the frontal regulation of attention. As a result, performance in frontal tasks requiring a high level of central control may worsen (Gotham et al., 1988; Kulisevsky et al., 1996). It has been hypothesized that continuous dopaminergic stimulation, such as can be achieved with dopaminergic agonists, may avoid or reduce motor fluctuations and dyskinesias by preventing or reversing sensitization induced by pulsate dopaminergic stimulation (Nutt, 2007). As a more continuous stimulation could improve the transient effects related to the LD plasma peak on the cognitive status of nondemented PD patients, we hypothesized that the rate of the rise in plasma LD may also play a role in cognitive fluctuations.

Controlled-release (CR) LD formulations have long been marketed to prolong the effects of the short half-life standard immediate-release (IR). In the present research, we tested the hypothesis that, a less acute increase in plasma LD concentrations associated to a smoother synaptic distribution of the dopamine formed from CR-LD should produce less marked cognitive swings than the rapid increase associated with IR-LD. We compared two oral LD formulations (IR-LD and CR-LD) with different time-to-peak concentrations to study whether the velocity of rising of LD plasma levels differently affected the cognitive status of long-term treated PD patients. We used a randomized, double blind, crossover design to study their cognitive performance and LD plasma levels immediately before and at various time points after the acute administration of IR- and CR-LD. As dopamine replacement is the core treatment of $\mathrm{PD}$ and most $\mathrm{PD}$ patients are treated with $\mathrm{LD}$, better characterization of cognitive fluctuations and their pharmacological response could contribute to substantial improvements in the well-being of PD patients (Schrag et al., 2000).

\section{METHODS}

\section{Research Participants}

All participants were outpatients regularly attending the Movement Disorders Unit at Sant Pau Hospital (Autonomous University of Barcelona) who gave written informed consent to a protocol approved by the local Institutional Ethics Committee. Patients were evaluated by qualified neurologists (B.P.S. and J.K.) to confirm the diagnosis of idio- 
pathic PD (Hughes et al., 1992). Those who presented marked motor fluctuations to oral LD (dose failure episodes or unpredictable response to oral LD) or severe dyskinesias that could interfere with test performance or results, were excluded. Two weeks before the experimental sessions, all participants underwent clinical interview with the patient and caregiver and a baseline neuropsychological study using a comprehensive battery of tests targeting memory, language, praxis, gnosis, and executive functions. Dementia was formally excluded using the 294.1 criteria of the Diagnostic and Statistical Manual of Mental Disorders, revised Fourth Edition (DSM IV-TR) (American Psychiatric Association, 1994). We also excluded those subjects who presented a score $\leq 24$ on the Mini-Mental State Examination (MMSE) (Folstein et al., 1975), had a history of current primary psychiatric illness or Axis I diagnoses according to the Structured Clinical Interview for DSM-IV (First, 1995), or had taken sedative or antidepressant medication in the 4 weeks before the first session. Additionally, as we aimed to investigate cognitive swings in a PD sample with no obvious cognitive fluctuations, we used a semi-structured questionnaire to exclude subjects complaining of acute mood or cognitive fluctuations in response to dopaminergic medication. The following written questions were specifically addressed both to the patient and caregiver: 1) "Do you, or does the patient appear to, experience some changes in mood (e.g., more depressed, happier) after taking a dose of antiparkinsonian medication?; 2) "Do you, or does the patient appear to, experience changes in concentration, and 3) "Do you, or does the patient appear to, feel transitorily confused after taking a dose of antiparkinsonian medication?" If the patient or the family member answered "yes" to any one of these questions, the patient was excluded.

\section{Study Design}

We used a randomized, double blind, crossover design for the comparison of two therapeutic interventions-immediaterelease (IR) and controlled-release (CR) LD—acutely administered at a 2-week interval.

By plotting the acute cognitive changes after each LD treatment, we aimed to test the hypothesis that a less acute increase in plasma LD concentrations-possibly associated with a smoother increase of central dopamine-should produce less marked cognitive swings than a rapid increase. Primary outcome measures were the performance over time of four different cognitive executive tests (WCST, Sternberg memory test, Stroop test and Tower of Hanoi). The secondary outcome measures were the changes over time in LD plasma levels and motor status.

\section{Procedure}

The study was carried out at the Sant Pau Center for Drug Research. A practice session using similar cognitive tests was conducted the day before the first experimental session aimed at minimizing possible learning effects (McCaffrey \& West- ervelt, 1995) and familiarizing the subjects with the setting. Experimental sessions were conducted after overnight withdrawal of all antiparkinsonian medication ("practical off") (Rodriguez-Oroz et al., 2005). Usual nonparkinsonian medication was unchanged between sessions.

Randomization of treatment (IR-LD or CR-LD) was drawn up by the statistician (I.G.) using Greco-Latin square designs. A pharmacist formulated LD capsules matched in size, color, shape, and appearance, and concealed allocations from investigators by securing treatment codes. To obtain a predictable and comparable motor effect using formulations with different bioavailability, LD capsules corresponded to $50 \%$ (IR-LD; Sinemet ${ }^{\circledR}$; levodopa: carbidopa, $4: 1 ; 99 \%$ bioavailability) or $70 \%$ (CR-LD; Sinemet CR ${ }^{\circledR}$; levodopa: carbidopa, 4:1; $71 \%$ bioavailability) (Yeh et al., 1989) of the usual total daily LD dose for each individual patient (see Table 1) (Kulisevsky et al., 1996).

The trial consisted of two experimental 8-hr sessions. These started at 8.30 AM and followed a fixed order of eight assessments of LD plasma levels and motor status (UPDRS-III) obtained before (at $-1 \mathrm{hr}$, pre-LD value) and at fixed testing times $(+0.5 \mathrm{hr},+1 \mathrm{hr},+2 \mathrm{hr},+2.5 \mathrm{hr}$, $+3.5 \mathrm{hr},+5 \mathrm{hr}$, and $+6 \mathrm{hr}$ ) after LD challenge. Cognitive tests were administered in a counterbalanced manner at four different testing times: at $-1 \mathrm{hr},+1 \mathrm{hr}, 2.5 \mathrm{hr}$, and $+5 \mathrm{hr}$ of drug administration. The investigator responsible for seeing the patients (B.P.S.) allocated the number on entry to the study, and at $0 \mathrm{hr}$, either an IR-LD or a CR-LD dose was dispensed to the patient depending on the randomization schedule. The same blinded investigator administered all cognitive tests and UPDRS scales in each session. The randomization codes were revealed to the investigator once recruitment, data collection and LD plasma levels were completed. Tests evaluating executive function were selected in view of the following characteristics: (1) brevity $(\sim 0.45$ $1 \mathrm{hr})$; (2) sensitivity to detect subtle cognitive changes in

Table 1. Characteristics of patients

\begin{tabular}{lc}
\hline \hline Number of patients & 14 \\
Sex & 7 men, 7 women \\
Age, y & $61.6(2.5)$ \\
Daily dose of LD, mg & $628.8(85.7)$ \\
Mean dose of IR-LD per session, mg & $276.9(35.6)$ \\
Mean dose of CR-LD per session, mg & $392.3(51.7)$ \\
Hoehn \& Yahr stage & $2.2(.1)$ \\
Disease duration, years & $7.15(1)$ \\
Duration of LD treatment, months & $56.1(11.2)$ \\
Concomitant treatment with & 12 patients \\
$\quad$ dopamine agonists & \\
UPDRS-III score (motor subscale)* & $30.6(2.9)$ \\
MMSE & $27.6(.5)$ \\
BDI & $11.7(1.5)$ \\
\hline \hline
\end{tabular}

Note. UPDRS = Unified Parkinson's Disease Rating Scale; MMSE = Mini-Mental State Examination; BDI = Beck Depression Inventory; ${ }^{*}$ The UPDRS motor subscale was evaluated during the "on" period; Data are given as mean (standard error mean). 
executive tasks often impaired in PD (Brown and Marsden, 1990; Gotham et al., 1988; Taylor et al., 1986); and (3) availability of at least four alternate forms to further minimize the test-retest effect (McCaffrey and Westervelt, 1995). We used computerized versions of the Wisconsin Card Sorting Test (WCST) to evaluate mental set-shifting and problem solving (Heaton et al., 1993), the Sternberg memory test (2, 4, and 6-digits) to explore short-term retention and manipulation of information within working memory (Sternberg, 1966), and the Stroop test to evaluate visual selective attention (Golden, 1978). Planning and procedural learning were explored with a manual version of the Tower of Hanoi (Simon, 1975). In the computerized version of WCST, the same 128 cards were used in all trials. However, the matching categories (color, shape, number) followed a different random sequence at each testing time. In the computerized version of the Stroop test, the stimuli (colored asterisks in Part 1 and the names of colors in Part 2) were randomly presented on the computer screen at each testing time. The presentation of stimuli was randomized by computer program for both these tests. Using variables considered for the WCST were the number of completed categories and perseverative errors. For the Sternberg memory test we considered the number of correct responses and the reaction time (RT) expressed in milliseconds (ms). For the Stroop test, we considered the number of correct responses in Part 1 (Color-Color) and Part 2 (Color of the words, or Stroop test with interference), RT for each stimulus, and the "Stroop Effect" calculated as the difference in RT of Part 2 minus Part 1 ("Stroop Effect" considered positive with maximal difference of $250 \mathrm{~ms}$ ). Variables considered for the Tower of Hanoi were time (maximum $300 \mathrm{~s}$ ) and number of movements (steps) made to move from the initial position to the predetermined position. Blood samples to determine the pharmacokinetic variables of LD—peak plasma concentration $\left(C_{\max } ; \mathrm{ng} / \mathrm{ml}\right)$ and time to occurrence of $C_{\max }\left(T_{\max } ; \mathrm{h}\right)$ -were obtained and analyzed as previously described (Kulisevsky et al., 1996). Pre-LD mood and mood state during the last week were assessed immediately before each session using a visual analogue scale for mood (VAS-M) (McCormack et al., 1988) and the BDI (Beck Depression Inventory) (Beck et al., 1961).

\section{Sample Size and Data Analysis}

The planning of the sample size was based on information from our previous work where 20 patients were studied (Kulisevsky et al., 1996). Taking into account the results of this study using a variable measured with an interval scale (variability and minimum relevant difference) and the crossover design of the present research, and establishing a probability of a Type I error $(\alpha)=.05$, and a bilateral hypothesis, we calculated a minimum sample size of 12 patients. We used a high corrector coefficient (0.5) to compensate for exclusions and dropouts, and planned to include up to 18 patients.

Statistical analyses of cognitive frontal performance were completed in two steps. First, a Student's paired $t$ test for
pre-LD data obtained in each session was applied to assess comparability of the starting point for each experimental intervention. Second, a repeated-measures two-way analysis of variance (ANOVA) to the differences between data at the different time-points after treatment administration in relation to pre-LD was used. Factors considered were type of medication (two levels: IR-LD and CR-LD), time (three levels: $1 \mathrm{hr}$-pre, $2.5 \mathrm{hr}$-pre, and $5 \mathrm{hr}$-pre) and the interaction between the two. Greenhouse-Geisser $\varepsilon$ correction was applied when necessary. When suitable, descriptive pairwise comparisons were performed using Student's paired $t$ test, not adjusted for multiple testing. The original degrees of freedom $(d f)$ and corrected $p$ values are given in the Results section. The $T_{\max }$ of LD curves was evaluated with nonparametric (Wilcoxon) test. The level of significance in all tests was $5 \%(p<.05$, two-tailed test). We analyzed data using SPSS (V-14).

\section{RESULTS}

Over 3 months, 82 patients were evaluated for eligibility, 16 of whom (intention-to-treat sample) were randomized: eight were allocated first to IR-LD and eight to CR-LD. Of these, 14 patients completed the study (per-protocol analysis sample), yielding a high adherence rate (14/16). Two patients (two women) withdrew from interventions during the first treatment period: one, who received CR-LD first, at her own request due to an unexpected family problem, and the second as the result of an episode of vomiting $1 \mathrm{hr}$ after taking IR-LD. These two patients were not analyzed because they did not perform any cognitive tests under study medications. No serious adverse events occurred during the study. No patient was taking both IR- and CR-LD at the time of entering the trial. Table 1 shows the patients' demographic and clinical data.

\section{Pre-LD Evaluations}

Patients showed no significant pre-LD differences on mood scores (BDI and VAS-M) between the two experimental sessions (Table 2). There were no significant pre-LD differences on cognitive scores even though the patients, before receiving $\mathrm{CR}-\mathrm{LD}$, performed poorer than the same patients

Table 2. Mood evaluation: Pre-LD values before each session

\begin{tabular}{llcc}
\hline \hline & & & $\begin{array}{c}p \text { value } \\
\text { (Student's } t \text { test) }\end{array}$ \\
\hline BDI & IR-LD session & $11.7(1.5)$ & $\mathrm{ns}$ \\
& CR-LD session & $12.3(1.8)$ & $\mathrm{n}$ \\
VAS-M & IR-LD session & $5.6(.3)$ & $\mathrm{ns}$ \\
& CR-LD session & $5.5(.4)$ & \\
\hline \hline
\end{tabular}

Note. BDI = Beck Depression Inventory; VAS-M = Visual analogue scale for mood; ns = nonsignificant. Data are given as mean (standard error mean). 
before receiving IR-LD, as can be seen on Table 3. Thus, there were comparable experimental conditions at the starting point for each type of medication.

\section{LD Plasma Levels}

The mean dose of IR-LD and CR-LD administered to patients in each session is shown in Table 1. No significant differences were obtained in the peak concentration $C_{\max }$ of the two LD formulations (IR: $4510 \pm 2737 \mathrm{ng} / \mathrm{ml}$; CR: $4825 \pm$ $3102 \mathrm{ng} / \mathrm{ml} ; p=.58)$. The median $T_{\max }$ of CR-LD was delayed with regard to IR-LD (IR: $1 \mathrm{hr}$, range 1-2.25; CR: $2 \mathrm{hr}$, range 1.5-2.5) (Wilcoxon test: $p=.04$ ). No significant differences were observed in the slope of the plasma concentrations of the elimination phase (IR: $8.32 \pm 6.62$; CR: $5.03 \pm 3.87 ; p=.16$ ).

\section{Motor Status}

The UPDRS-III scores consistently improved over time ( $p=$ .003). The patients' best motor status was reached at the same time point with IR-LD as with CR-LD (at $+2.5 \mathrm{hr}$ ), and its magnitude was similar with both types of LD [mean UPDRS-III score for IR-LD $=17$ (8.3), CR-LD $=18.3$ $(9.7) ; p=.33]$.

\section{COGNITIVE PERFORMANCE}

Data of cognitive performance over sessions (mean scores and $p$ values) are presented in Table 3.

\section{WCST}

\section{Categories}

ANOVA analysis showed no significant results but a marginal medication effect $\left[F_{\text {medication }}: 3.31 ; d f=1,13 ; p=\right.$ $.085 . F_{\text {time }}: .79: d f=2,26 ; p=.454 . F_{\text {interaction }}: .14 ; d f=2$, $26 ; p=.85]$ characterized by somewhat greater improvement in the CR condition. See Figure 1.

\section{Perseverative errors}

Although no significant results were evidenced after applying ANOVA analysis $\left[F_{\text {medication }}: 3.14 ; d f=1,13 ; p=.104\right.$. $F_{\text {time }}: 1.70: d f=2,26 ; p=.210 . F_{\text {interaction }}: .02 ; d f=2,26$; $p=.972]$, somewhat fewer errors were produced after CR-LD than after IR-LD in all recording times. Mean maximum difference from pre-treatment values was -9.5 errors for CR-LD and -4.8 errors for IR-LD (Figure 2).

\section{Sternberg Memory Test}

There were no significant changes for correct responses and RT in the 2- and 4-digit subsets. However, a significant effect of medication type was observed in the ANOVA analysis applied to the RT data of the 6-digit subset $\left[F_{\text {medication }}\right.$ : $5.83 ; d f=1,13 ; p=.033 . F_{\text {time }}: 2.31: d f=2,26 ; p=.124$. $\left.F_{\text {interaction }} .10 ; d f=2,26 ; p=.880\right]$. This effect was indicative of a reduction in RT with CR-LD $(-221 \mathrm{~ms}$ from pre-LD at $+5 \mathrm{hr}$ ) and an increase in RT with IR-LD

Table 3. Raw data for cognitive tests scores over IR-LD and CR-LD sessions

\begin{tabular}{|c|c|c|c|c|c|c|}
\hline & & & Pre-LD (-1hr) & $+1 \mathrm{hr}$ & $+2.5 \mathrm{hr}$ & $+5 \mathrm{hr}$ \\
\hline \multirow[t]{4}{*}{ WCST } & \multirow[t]{2}{*}{ Categories } & IR-LD & $4.9(.2)$ & $4.8(.3)$ & $5.1(.2)$ & $5.0(.3)$ \\
\hline & & CR-LD & $4.6(.2)$ & $5.0(.3)$ & $5.0(.3)$ & $5.2(.3)$ \\
\hline & \multirow{2}{*}{$\begin{array}{l}\text { Perseverative } \\
\text { errors }\end{array}$} & IR-LD & $27.9(3.1)$ & $27.6(3.3)$ & $25.0(3.5)$ & $23.1(3.5)$ \\
\hline & & CR-LD & $32.7(3.6)$ & $27.2(4.4)$ & $25.5(4.2)$ & $23.2(3.7)$ \\
\hline \multirow{4}{*}{$\begin{array}{l}\text { Sternberg } \\
\text { memory test }\end{array}$} & \multirow{4}{*}{$\begin{array}{l}\text { Correct } \\
\text { responses } \\
\text { RT }\end{array}$} & IR-LD & $7.8(.4)$ & $7.5(.5)$ & $7.8(.4)$ & $7.5(.5)$ \\
\hline & & CR-LD & $7.3(.5)$ & $7.1(.6)$ & $7.5(.4)$ & $7.2(.4)$ \\
\hline & & IR-LD & 1509.7 (139.8) & $1829.3(331.2)$ & $1741.5(306)$ & $1961.0(366.1)$ \\
\hline & & CR-LD & $1924.2(299.5)$ & $1650.4(254.3)$ & $1561.3(163.6)$ & $1702.4(233.8)$ \\
\hline \multirow[t]{10}{*}{ Stroop test } & Part 1 & IR-LD & $19.3(.3)$ & $19.4(.2)$ & $19.5(.1)$ & $19.8(.1)$ \\
\hline & Correct responses & CR-LD & $19.7(.1)$ & $19.6(.2)$ & $19.3(.2)$ & $19.7(.1)$ \\
\hline & Part 1 & CR-LD & $1113.0(19.5)$ & $1087.2(78.6)$ & $1020.4(57)$ & $1057.0(79.7)$ \\
\hline & RT & IR-LD & $1119.5(77.2)$ & 1045.4 (77.9) & 968.3 (103) & $1062.8(83.5)$ \\
\hline & Part 2 & IR-LD & $19.3(.3)$ & $19.5(.2)$ & $19.5(.1)$ & $19.8(.1)$ \\
\hline & Correct responses & CR-LD & $19.7(.1)$ & $19.6(.2)$ & $19.3(.2)$ & $19.7(.1)$ \\
\hline & Part 2 & IR-LD & $1204.1(92.7)$ & $1069.8(62)$ & $1062.1(61.8)$ & $1186.5(191.4)$ \\
\hline & RT & CR-LD & $1162.1(72.4)$ & $1099.7(83.1)$ & $1110.5(64.7)$ & $1107.1(82.9)$ \\
\hline & Stroop effect & IR-LD & $104.4(55.7)$ & $-13.6(36.6)$ & $53.0(18.9)$ & $245.0(105.5)$ \\
\hline & (RT of Part 2 minus Part 1 ) & CR-LD & $97.8(51.3)$ & $12.1(33.6)$ & $87.5(23.5)$ & $73.3(28.6)$ \\
\hline \multirow[t]{4}{*}{ Tower of Hanoi } & Time & IR-LD & $205.3(29.8)$ & $207.8(28.6)$ & $215.0(29.7)$ & $205.1(25.8)$ \\
\hline & (seconds) & CR-LD & $195.9(26.6)$ & $230.4(25.2)$ & $210.3(25.2)$ & $194.5(29.7)$ \\
\hline & Steps & IR-LD & $28.9(4.0)$ & $31.8(3.9)$ & $35.5(6.6)$ & $29.0(3.6)$ \\
\hline & & CR-LD & $28.6(4.5)$ & $30.6(5.1)$ & $28.5(3.1)$ & $31.6(3.4)$ \\
\hline
\end{tabular}

Note . WCST $=$ Wisconsin Card Sorting Test; RT = reaction time; Stroop Test Part $1=$ Color-Color; Stroop Test Part $2=$ Color of the words, or Stroop test with interference; ns = nonsignificant. Data are given as mean (standard error mean). 


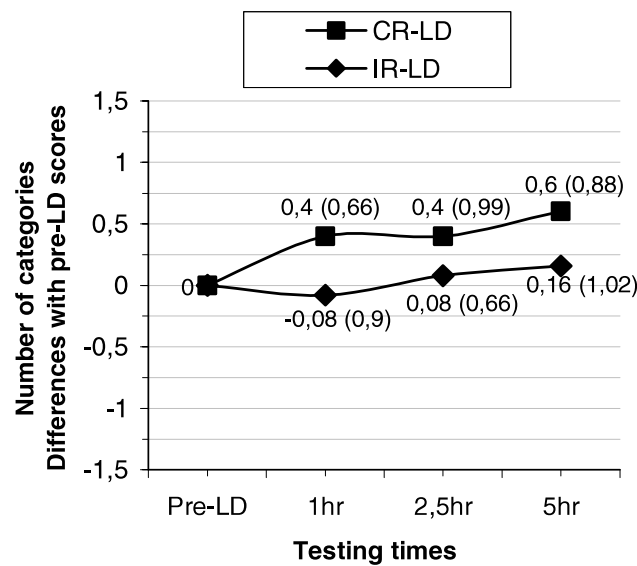

Fig. 1. WCST. Evolution over time of differences in relation to pre-LD score of number of categories obtained with IR-LD and CR-LD. Data are given as mean (standard deviation).

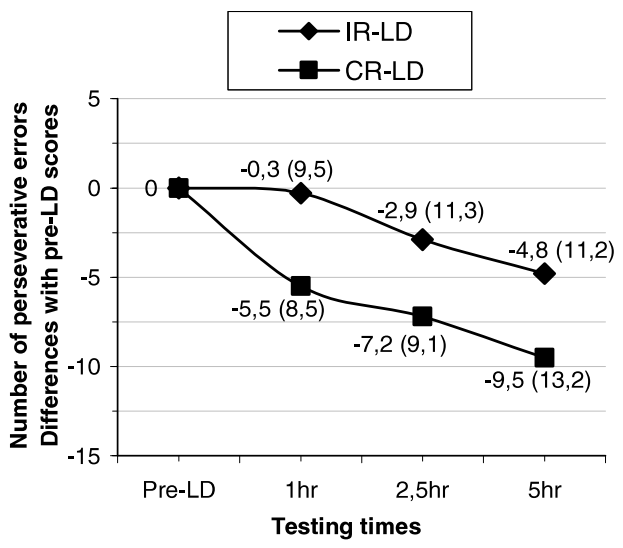

Fig. 2. WCST. Evolution over time of differences in relation to pre-LD score of number of perseverative errors committed with IR-LD and CR-LD. Data are given as mean (standard deviation).

( $+451 \mathrm{~ms}$ from pre-LD at $+5 \mathrm{hr})$. Pair-wise comparisons were significant for nearly all times posttreatment $[+1 \mathrm{hr}$ : $p=.036 ;+2.5$ hr: $p=.082 ;+5$ hr: $p=.032$ ] (Figure 3).

\section{Stroop Test and Tower of Hanoi}

No significant changes were observed for any of the variables considered in these two tasks.

\section{DISCUSSION}

In this study, we explored whether fluctuations in executive function after LD challenge in PD were related to the pharmacokinetic profile of oral LD and to tasks associated with distinct cognitive processes of the frontal-basal ganglia circuits. We found that frontal-related executive performance of PD patients appeared to differ after LD challenge, depending on the time-to-peak plasma concentration of LD and on the specific demands of the explored task. A slower rise in

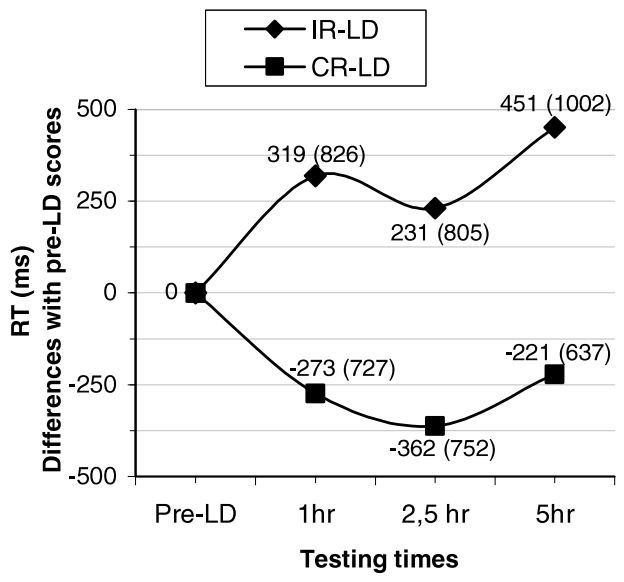

Fig. 3. Sternberg memory test (6-digit subset). Evolution over time of differences in relation to pre-LD score reaction time (RT) on the whole sample of patients ( $p=.03$ time). Data are given as mean (standard deviation).

LD plasma levels appeared to have a more favorable impact on cognitive performance. This was evidenced by a consistently better manipulation of information within working memory and favored a set-shifting task, without affecting planning or visual selective attention tasks.

To our knowledge, this is the first attempt to compare the acute cognitive effects of faster versus slower dopaminergic stimulation in PD. Results demonstrating significant fluctuations in cognitive performance and differences between treatments are strengthened because we only included patients with no noticeable cognitive or mood fluctuations associated to LD intake. We were, therefore, able to demonstrate that clinically inappreciable cognitive swings are not a rare phenomenon in PD. Monitoring plasma LD levels added further consistency to the obtained results by confirming that both formulations had the expected pharmacokinetic differences, with CR-LD having a significantly longer $T_{\max }$ than regular IR-LD. Motor monitoring showing that the best achieved motor status of PD patients was similar with both LD formulations served to minimize confounding factors that can emerge because of motor influence on neuropsychological performance. Some limitations should be considered. The first is the relatively small sample of patients. Sample size was, nevertheless, similar to other studies dealing with cognitive effects of LD (Cools et al., 2002; Fournet et al., 2000; Grossman et al., 2001; Lange et al., 1992; Poewe et al., 1991; Skeel et al., 2001), and in the current research this was partially compensated by the crossover design. Second, the most appropriate neuropsychological measures for capturing cognitive swings in PD patients are unknown. We therefore selected tasks known to be impaired in PD patients, allowing for repeated administration, and previously used in acute pharmacological studies in PD (Cools et al., 2002; Gotham et al., 1988; Kulisevsky et al., 1996; Lange et al., 1992; Poewe et al., 1991). Third, although our study has the strength of the crossover design, the overnight washout of the dopaminergic medications can 
not be sufficient to eliminate the relative impact of the long duration response to LD (Fahn, 2006). Thus, the results of the present research would apply specifically for the shortduration response to LD (Nutt and Holford, 1996). Nevertheless, as it would be unethical to withdraw antiparkinsonian drugs for prolonged periods of time, most studies use the "practical-off" (Rodriguez-Oroz et al., 2005) to address the acute cognitive effects of LD (Costa et al., 2003; Fera et al., 2007). Fourth, although the improvement observed in WCST over time might be related to a test-retest practice effect, we consider this issue is overcome by the repeated preexperiment exposure to elicit plateau performance, and by the crossover design. Finally, dyskinetic patients may have more plastic changes in the motor component of the frontobasal ganglia circuits related to chronic nonphysiologic dopaminergic replacement (Mouradian et al., 1989). They might also be more prone to exhibit cognitive swings if similar changes occur in "cognitive" circuits, and thus be at higher risk to exhibit cognitive oscillations. As we excluded patients with severe dyskinesias for methodological reasons (interference of involuntary movements with test performance) we are unable to conclude whether or not they differ in their IR/IC response. Further research focusing on this subgroup of patients should examine this point.

The most consistent result of the study was observed in the Sternberg test where patient performance differed significantly with each type of LD. Improved performance with CR-LD in the Sternberg test consisted of a faster production of responses, without significant changes in accuracy. Interestingly, while there was a significant improvement in the 6-digit subset under CR-LD, we did not observe changes in the 2- and 4-digit subsets with either type of LD. Moreover, the profile of the response curve in the Sternberg 6-digit was indicative of a dissociated LD effect, with performance improving with CR- and worsening with IR-LD.

Although not significant, quantitative results of the WCST performance suggested a similar trend. Compared with performance under IR-LD, with CR-LD, patients completed more categories and committed fewer perseverative errors in the WCST. However, there was no significant change in performance with practice in any measure.

Overall, these findings further illustrate that LD may affect cognitive function differently depending on specific task demands (Cools et al., 2002; Kulisevsky et al., 1996). Specifically, results on the Sternberg working memory test show that the effects of LD can differ even within a single task (Frank et al., 2004; Shohamy et al., 2006). Negative effects of conventional LD on the 6- but not on the 2- and 4-digit subsets is in line with recent work showing impaired incremental learning with LD and no deficit when the patients perform the same task without medication or with decreased demands (Shohamy et al., 2006). Furthermore, our research indicates that CR-LD is not associated with this observed impairment (Shohamy et al., 2006) but with improved performance with respect to pre-LD. These findings are consistent with the hypothesis that LD-related impairment on specific highly demanding executive function tasks (Cools et al., 2002; Frank et al., 2004; Kulisevsky et al., 1996; Mattay et al., 2002; Poewe et al., 1991; Swainson et al., 2000) depends, at least in part, on the rapid rise of LD plasma levels. Thus, a less abrupt pattern of variation of dopamine concentration in the parkinsonian brain, such as that associated with a slower rise of LD plasma levels, might alleviate performance deficiencies associated to high LD plasma levels (Kulisevsky, 2000).

Our findings also further highlight the importance of identifying the individual components of interest from complex measures when evaluating cognitive responses to dopaminergic medication in PD (Cools, 2006; Shohamy et al., 2006). In the current research using four different executive function tasks related to individual components of the frontolimbic-basal ganglia circuits (Cools et al., 2002; Dagher et al., 2001; Egner and Hirsch, 2005; Schroeder et al., 2002), LD had a clear impact on performance in the Sternberg 6-digit test (a working memory task) and a marginal effect on the WCST (a set-shifting task), whereas the Stroop test (a task of visual selective attention) and the Tower of Hanoi (a planning task suggesting procedural learning) appeared largely unaffected. Thus, tests that have been proposed to measure the same general cognitive construct, namely executive function, may present a dissociated response to LD challenge (Cools, 2006; Shohamy et al., 2006). Moreover, we have previously observed (Kulisevsky et al., 1996) this dissociation between tests that have been proposed to measure the same specific construct (namely, inhibitory control) (Kosmidis et al., 2006), such as the WCST (with transitory worsening coinciding with the peak plasma LD levels) and the Stroop test (not affected by LD challenge). This may be explained by dependence on different frontosubcortical circuits: dorsolateral for the WCST and anterior cingulate for the Stroop test (Cools et al., 2002; Schroeder et al., 2002).

However, our results extend previous findings that conventional LD causes cognitive oscillations in patients with PD (Cools et al., 2003; Gotham et al., 1988; Kulisevsky et al., 1996; Mollion et al., 2003; Witjas et al., 2002). These oscillations depend on the cognitive complexity and the different demands of the requested task. Additionally, we demonstrate that the pharmacokinetic properties of different formulations of oral LD influence the susceptibility of PD patients to present cognitive oscillations.

Dopaminergic therapy, particularly with conventional IR-LD, is the current mainstay of therapy for the motor features of PD. The present research shows that a slower rise in LD plasma levels might diminish the risk of potential cognitive side effects of conventional LD in PD patients. This finding should be balanced against potential long-term motor side effects of commercially available CR formulations such as an increase in dyskinesias (Bejjani et al., 2000; de la Fuente-Fernández et al., 2004). Although this study deals with the acute effects of LD, it might have relevant implications for chronic treatment. The short-half life of the available LD formulations and the need to take repeated doses throughout the day continuously exposes many PD 
patients to synaptic overflow of LD (de la Fuente-Fernández et al., 2004) and to the risk of cognitive swings, chronically repeating the conditions of our experimental setting. Importantly, although score differences observed seem small, our results showing subclinical oscillations in cognition were obtained in a highly selected population without complaints of cognitive swings with LD. Patients who complain of cognitive swings are likely more affected with cognitive oscillations interfering in every-day life (Witjas et al., 2002). Improved formulations of LD are required to further avoid abrupt plasmatic changes and to obtain a more sustained half-life of LD plasma levels.

\section{ACKNOWLEDGMENTS}

We thank our patients for their invaluable help and the personnel at the Center for Drug Research for their contribution to this study. The authors do not report any conflict of interest. The work was partially supported by public research grants from "Fondo de Investigaciones Sanitarias" PI051916 and Centro de Investigaciones Biomédicas en Red-Enfermedades Neurodegenerativas (CIBERNED).

\section{REFERENCES}

American Psychiatric Association. (1994). Diagnostic and Statistical Manual of Mental Disorders (4th ed.). Washington, DC: American Psychiatric Association.

Bäckman, L., Ginovart, N., Dixon, R.A., Wahlin, T.B., Wahlin, A., Halldin, C., \& Farde, L. (2000). Age-related cognitive deficits mediated by changes in the striatal dopamine system. The American Journal of Psychiatry, 157, 635-637.

Beck, A.T., Ward, C.H., Mendelson, M., Mock, J., \& Erbaugh, J. (1961). An inventory for measuring depression. Archives of General Psychiatry, 4, 561-571.

Bejjani, B.P., Arnulf, I., Demeret, S., Damier, P., Bonnet, A.M., Houeto, J.L., \& Agid, Y. (2000). Levodopa-induced dyskinesias in Parkinson's disease: Is sensitization reversible? Annals of Neurology, 47, 655-658.

Brown, R.G. \& Marsden, C.D. (1990). Cognitive function in Parkinson's disease: From description to theory. Trends in Neuroscience, 13, 21-29.

Chase, T.N. \& Oh, J.D. (2000). Striatal dopamine- and glutamatemediated dysregulation in experimental parkinsonism. Trends in Neuroscience, 23, S86-S91.

Cools, R. (2006). Dopaminergic modulation of cognitive functionimplications for L-DOPA treatment in Parkinson's disease. Neuroscience and Biobehavioral Reviews, 30, 1-23.

Cools, R., Barker, R.A., Sahakian, B.J., \& Robbins, T.W. (2001). Enhanced or impaired cognitive function in Parkinson's disease as a function of dopaminergic medication and task demands. Cerebral Cortex, 11, 1136-1143.

Cools, R., Barker, R.A., Sahakian, B.J., \& Robbins, T.W. (2003). L-Dopa medication remediates cognitive inflexibility, but increases impulsivity in patients with Parkinson's disease. Neuropsychologia, 41, 1431-1441.

Cools, R., Stefanova, E., Barker, R.A., Robbins, T.W., \& Owen, A.M. (2002). Dopaminergic modulation of high-level cognition in Parkinson's disease: The role of the prefrontal cortex revealed by PET. Brain, 125, 584-594.
Costa, A., Peppe, A., Dell'Agnello, G., Carlesimo, G.A., Murri, L., Bonuccelli, U., \& Caltagirone, C. (2003). Dopaminergic modulation of visual-spatial working memory in Parkinson's disease. Dementia and Geriatric Cognitive Disorders, 15, 55-66.

Cropley, V.L., Fujita, M., Innis, R.B., \& Nathan, P.J. (2006). Molecular imaging of the dopaminergic system and its association with human cognitive function. Biological Psychiatry, 59, 898-907.

Dagher, A., Owen, A.M., Boecker, H., \& Brooks, D.J. (2001). The role of the striatum and hippocampus in planning: A PET activation study in Parkinson's disease. Brain, 124, 1020-1032.

Damier, P., Hirsch, E.C., Agid, Y., \& Graybiel, A.M. (1999). The substantia nigra of the human brain. II. Patterns of loss of dopamine-containing neurons in Parkinson's disease. Brain, 122 (Pt. 8), 1437-1448.

de la Fuente-Fernández, R., Lu, J.Q., Sossi, V., Jivan, S., Schulzer, M., Holden, J.E., Lee, C.S., Ruth, T.J., Calne, D.B., \& Stoessl, A.J. (2001). Biochemical variations in the synaptic level of dopamine precede motor fluctuations in Parkinson's disease: PET evidence of increased dopamine turnover. Annals of Neurology, 49, 298-303.

de la Fuente-Fernández, R., Sossi, V., Huang, Z., Furtado, S., Lu, J.Q., Calne, D.B., Ruth, T.J., \& Stoessl, A.J. (2004). Levodopainduced changes in synaptic dopamine levels increase with progression of Parkinson's disease: Implications for dyskinesias. Brain, 127, 2747-2754.

Dreher, J.C., Guigon, E., \& Burnod, Y. (2002). A model of prefrontal cortex dopaminergic modulation during the delayed alternation task. Journal of Cognitive Neuroscience, 14, 853-865.

Egner, T. \& Hirsch, J. (2005). The neural correlates and functional integration of cognitive control in a Stroop task. Neuroimage, $24,539-547$.

El-Ghundi, M., O’Dowd, B.F., \& George, S.R. (2007). Insights into the role of dopamine receptor systems in learning and memory. Reviews in the Neurosciences, 18, 37-66.

Emre, M. (2003). What causes mental dysfunction in Parkinson's disease? Movement Disorders, 18(Suppl. 6), S63-S71.

Fahn, S. (2006). Levodopa in the treatment of Parkinson's disease. Journal of Neural Transmission Supplementum, 1-15.

Fera, F., Nicoletti, G., Cerasa, A., Romeo, N., Gallo, O., Gioia, M.C., Arabia, G., Pugliese, P., Zappia, M., \& Quattrone, A. (2007). Dopaminergic modulation of cognitive interference after pharmacological washout in Parkinson's disease. Brain Research Bulletin, 74, 75-83.

First, M. (1995). Structured Clinical Interview for DSM-IV Axis Disorders, Patient Edition (SCID-P), Version 2. New York: New York State Psychiatric Institute, Biometrics Research.

Folstein, M.F., Folstein, S.E., \& McHugh, P.R. (1975). "Minimental state". A practical method for grading the cognitive state of patients for the clinician. Journal of Psychiatry Research, 12, 189-198.

Fournet, N., Moreaud, O., Roulin, J.L., Naegele, B., \& Pellat, J. (2000). Working memory functioning in medicated Parkinson's disease patients and the effect of withdrawal of dopaminergic medication. Neuropsychology, 14, 247-253.

Frank, M.J., Seeberger, L.C., \& O'Reilly, R.C. (2004). By carrot or by stick: Cognitive reinforcement learning in parkinsonism. Science, 306, 1940-1943.

Golden, C.J. (1978). Stroop Color and Word Test. Chicago, IL: Stoelting Co.

Goldman-Rakic, P.S., Muly, E.C., III., \& Williams, G.V. (2000). D(1) receptors in prefrontal cells and circuits. Brain Research. Brain Research Reviews, 31, 295-301. 
Gotham, A.M., Brown, R.G., \& Marsden, C.D. (1988). 'Frontal' cognitive function in patients with Parkinson's disease 'on' and 'off' levodopa. Brain, 111(Pt. 2), 299-321.

Grossman, M., Glosser, G., Kalmanson, J., Morris, J., Stern, M.B., \& Hurtig, H.I. (2001). Dopamine supports sentence comprehension in Parkinson's Disease. Journal of the Neurological Sciences, 184, 123-130.

Heaton, R.K., Chelune, G.I., Talley, L.L., Kay, G.G., \& Curtis, G. (1993). Wisconsin Card Sorting Test (WCST). Manual Revised and Expanded. Odessa, FL: Psychological Assessment Resources.

Hughes, A.J., Daniel, S.E., Kilford, L., \& Lees, A.J. (1992). Accuracy of clinical diagnosis of idiopathic Parkinson's disease: A clinico-pathological study of 100 cases. Journal of Neurology, Neurosurgery, and Psychiatry, 55, 181-184.

Janvin, C., Aarsland, D., Larsen, J.P., \& Hugdahl, K. (2003). Neuropsychological profile of patients with Parkinson's disease without dementia. Dementia and Geriatric Cognitive Disorders, $15,126-131$.

Jellinger, K. (1987). Neuropathological substrates of Alzheimer's disease and Parkinson's disease. Journal of Neural Transmission. Supplementum, 24, 109-129.

Jellinger, K.A. (2001). The pathology of Parkinson's disease. Advances in Neurology, 86, 55-72.

Kish, S.J., Shannak, K., \& Hornykiewicz, O. (1988). Uneven pattern of dopamine loss in the striatum of patients with idiopathic Parkinson's disease. Pathophysiologic and clinical implications. The New England Journal of Medicine, 318, 876-880.

Kosmidis, M.H., Bozikas, V.P., Zafiri, M., \& Karavatos, A. (2006). Shared cognitive processes underlying performance on the Wisconsin Card Sorting Test and the Stroop Test in patients with schizophrenia: A measurement artifact? Neuroscience Letters, 409, 234-238.

Kulisevsky, J. (2000). Role of dopamine in learning and memory: Implications for the treatment of cognitive dysfunction in patients with Parkinson's disease. Drugs \& Aging, 16, 365-379.

Kulisevsky, J., Avila, A., Barbanoj, M., Antonijoan, R., Berthier, M.L., \& Gironell, A. (1996). Acute effects of levodopa on neuropsychological performance in stable and fluctuating Parkinson's disease patients at different levodopa plasma levels. Brain, 119(Pt 6), 2121-2132.

Lange, K.W., Robbins, T.W., Marsden, C.D., James, M., Owen, A.M., \& Paul, G.M. (1992). L-dopa withdrawal in Parkinson's disease selectively impairs cognitive performance in tests sensitive to frontal lobe dysfunction. Psychopharmacology (Berl), 107, 394-404.

Lees, A.J. \& Smith, E. (1983). Cognitive deficits in the early stages of Parkinson's disease. Brain, 106(Pt 2), 257-270.

Malapani, C., Pillon, B., Dubois, B., \& Agid, Y. (1994). Impaired simultaneous cognitive task performance in Parkinson's disease: A dopamine-related dysfunction. Neurology, 44, 319-326.

Malapani, C., Rakitin, B., Levy, R., Meck, W.H., Deweer, B., Dubois, B., \& Gibbon, J. (1998). Coupled temporal memories in Parkinson's disease: A dopamine-related dysfunction. Journal of Cognitive Neuroscience, 10, 316-331.

Mattay, V.S., Tessitore, A., Callicott, J.H., Bertolino, A., Goldberg, T.E., Chase, T.N., Hyde, T.M., \& Weinberger, D.R. (2002). Dopaminergic modulation of cortical function in patients with Parkinson's disease. Annals of Neurology, 51, 156-164.

McCaffrey, R.J. \& Westervelt, H.J. (1995). Issues associated with repeated neuropsychological assessments. Neuropsychology Review, 5, 203-221.
McCormack, H.M., Horne, D.J., \& Sheather, S. (1988). Clinical applications of visual analogue scales: A critical review. Psychological Medicine, 18, 1007-1019.

Mizoguchi, K., Yuzurihara, M., Ishige, A., Sasaki, H., Chui, D.H., \& Tabira, T. (2000). Chronic stress induces impairment of spatial working memory because of prefrontal dopaminergic dysfunction. The Journal of Neuroscience, 20, 1568-1574.

Mollion, H., Ventre-Dominey, J., Dominey, P.F., \& Broussolle, E. (2003). Dissociable effects of dopaminergic therapy on spatial versus non-spatial working memory in Parkinson's disease. Neuropsychologia, 41, 1442-1451.

Monchi, O., Petrides, M., Doyon, J., Postuma, R.B., Worsley, K., \& Dagher, A. (2004). Neural bases of set-shifting deficits in Parkinson's disease. The Journal of Neuroscience, 24, 702-710.

Mouradian, M.M., Heuser, I.J., Baronti, F., Fabbrini, G., Juncos, J.L., \& Chase, T.N. (1989). Pathogenesis of dyskinesias in Parkinson's disease. Annals of Neurology, 25, 523-526.

Nutt, J.G. (2007). Continuous dopaminergic stimulation: Is it the answer to the motor complications of Levodopa? Movement Disorders, 22, 1-9.

Nutt, J.G. \& Holford, N.H. (1996). The response to levodopa in Parkinson's disease: Imposing pharmacological law and order. Annals of Neurology, 39, 561-573.

Oh, J.D., Geller, A.I., Zhang, G., \& Chase, T.N. (2003). Gene transfer of constitutively active protein kinase $\mathrm{C}$ into striatal neurons accelerates onset of levodopa-induced motor response alterations in parkinsonian rats. Brain Research, 971, 18-30.

Olanow, C.W., Agid, Y., Mizuno, Y., Albanese, A., Bonuccelli, U., Damier, P., De Yebenes, J., Gershanik, O., Guttman, M., Grandas, F., Hallett, M., Hornykiewicz, O., Jenner, P., Katzenschlager, R., Langston, W.J., LeWitt, P., Melamed, E., Mena, M.A., Michel, P.P., Mytilineou, C., Obeso, J.A., Poewe, W., Quinn, N., Raisman-Vozari, R., Rajput, A.H., Rascol, O., Sampaio, C., \& Stocchi, F. (2004). Levodopa in the treatment of Parkinson's disease: Current controversies. Movement Disorders, 19, 997-1005.

Peavy, G.M., Salmon, D., Bear, P.I., Paulsen, J.S., Cahn, D.A., Hofstetter, C.R., Kaplan, E.F., Delis, D.C., \& Shult, C.W. (2001). Detection of mild cognitive deficits in Parkinson's disease patients with the WAIS-R NI. Journal of the International Neuropsychological Society, 7, 535-543.

Poewe, W., Berger, W., Benke, T., \& Schelosky, L. (1991). Highspeed memory scanning in Parkinson's disease: Adverse effects of levodopa. Annals of Neurology, 29, 670-673.

Rodriguez-Oroz, M.C., Obeso, J.A., Lang, A.E., Houeto, J.L., Pollak, P., Rehncrona, S., Kulisevsky, J., Albanese, A., Volkmann, J., Hariz, M.I., Quinn, N.P., Speelman, J.D., Guridi, J., Zamarbide, I., Gironell, A., Molet, J., Pascual-Sedano, B., Pidoux, B., Bonnet, A.M., Agid, Y., Xie, J., Benabid, A.L., Lozano, A.M., Saint-Cyr, J., Romito, L., Contarino, M.F., Scerrati, M., Fraix, V., \& Van Blercom, N. (2005). Bilateral deep brain stimulation in Parkinson's disease: A multicentre study with 4 years followup. Brain, 128(Pt. 10), 2240-2249.

Schrag, A., Jahanshahi, M., \& Quinn, N. (2000). What contributes to quality of life in patients with Parkinson's disease? Journal of Neurology, Neurosurgery, and Psychiatry, 69, 308-312.

Schroeder, U., Kuehler, A., Haslinger, B., Erhard, P., Fogel, W., Tronnier, V.M., Lange, K.W., Boecker, H., \& Ceballos-Baumann, A.O. (2002). Subthalamic nucleus stimulation affects striato-anterior cingulate cortex circuit in a response conflict task: A PET study. Brain, 125(Pt. 9), 1995-2004. 
Shohamy, D., Myers, C.E., Geghman, K.D., Sage, J., \& Gluck, M.A. (2006). L-dopa impairs learning, but spares generalization, in Parkinson's disease. Neuropsychologia, 44, 774-784.

Simon, H.A. (1975). The functional equivalence of problem solving skills. Cognitive Psychology, 7, 268-288.

Skeel, R.L., Crosson, B., Nadeau, S.E., Algina, J., Bauer, R.M., \& Fennell, E.B. (2001). Basal ganglia dysfunction, working memory, and sentence comprehension in patients with Parkinson's disease. Neuropsychologia, 39, 962-971.

Sternberg, S. (1966). High-speed scanning in human memory. Science, 153, 652-654.

Swainson, R., Rogers, R.D., Sahakian, B.J., Summers, B.A., Polkey, C.E., \& Robbins, T.W. (2000). Probabilistic learning and reversal deficits in patients with Parkinson's disease or frontal or temporal lobe lesions: Possible adverse effects of dopaminergic medication. Neuropsychologia, 38, 596-612.

Taylor, A.E., Saint-Cyr, J.A., \& Lang, A.E. (1986). Frontal lobe dysfunction in Parkinson's disease. The cortical focus of neostriatal outflow. Brain, 109(Pt. 5), 845-883.

Vijayraghavan, S., Wang, M., Birnbaum, S.G., Williams, G.V., \& Arnsten, A.F. (2007). Inverted-U dopamine D1 receptor actions on prefrontal neurons engaged in working memory. Nature Neuroscience, 10, 376-384.
Volkow, N.D., Gur, R.C., Wang, G.J., Fowler, J.S., Moberg, P.J., Ding, Y.S., Hitzemann, R., Smith, G., \& Logan, J. (1998). Association between decline in brain dopamine activity with age and cognitive and motor impairment in healthy individuals. The American Journal of Psychiatry, 155, 344-349.

Westin, J.E., Andersson, M., Lundblad, M., \& Cenci, M.A. (2001). Persistent changes in striatal gene expression induced by longterm L-DOPA treatment in a rat model of Parkinson's disease. The European Journal of Neuroscience, 14, 1171-1176.

Williams, G.V. \& Goldman-Rakic, P.S. (1995). Modulation of memory fields by dopamine D1 receptors in prefrontal cortex. Nature, 376, 572-575.

Witjas, T., Kaphan, E., Azulay, J.P., Blin, O., Ceccaldi, M., Pouget, J., Poncet, M., \& Chérif, A.A. (2002). Nonmotor fluctuations in Parkinson's disease: Frequent and disabling. Neurology, 59, 408-413.

Yeh, K.C., August, T.F., Bush, D.F., Lasseter, K.C., Musson, D.G., Schwartz, S., Smith, M.E., Titus, D.C. (1989). Pharmacokinetics and bioavailability of Sinemet CR: A summary of human studies. Neurology, 39 (Suppl. 2), 25-38. 